\title{
DESAFIOS E PERPERCTIVAS DA CABOTAGEM NO BRASIL NO TRANSPORTE DE CARGAS
}

Rodrigo de Lima Souza, Claudio José Donato, Irene Caires da Silva

Universidade do Oeste Paulista - UNOESTE, MBA em Logística, Presidente Prudente, SP. E-mail: rodrigolimasouza@yahoo.com.br; claudio.donato@hotmail.com; irene@unoeste.br

\section{RESUMO}

O objetivo desta pesquisa é de relatar os desafios e as perspectivas dos transportes por Cabotagem em um âmbito nacional, utilizando como base de pesquisa o transporte de cargas, desafios rotineiros como falta de estrutura nos portos já existentes no Brasil, falta de incentivos pelos órgãos responsáveis e o futuro do serviço. A metodologia utilizada neste trabalho foi de pesquisa bibliográfica, destacando o conceito de logística de transportes de cargas pelo modal Hidroviário para as atividades de movimentação de cargas.

Palavras-chaves: logística, modal hidroviário, transporte de carga.

\section{CHALLENGES AND PROSPECTS OF CABOTAGE IN BRAZIL IN CARGO TRANSPORT}

\begin{abstract}
The objective of this research is to report on the challenges and perspectives of cabotage transport in a national context, using cargo transportation as a basis for research, routine challenges such as lack of structure in ports already existing in Brazil, lack of incentives by the responsible agencies And the future of service. The methodology used in this work was a bibliographical research, highlighting the concept of cargo transportation logistics by the modal Waterway for cargo handling activities.
\end{abstract}

Keywords: logistics, modal waterway, cargo transportation.

\section{INTRODUÇÃO}

O Transporte de cargas pelo Brasil se torna um desafio imenso devido o seu tamanho territorial de dimensões gigantescas e de terrenos dos mais variados possíveis, para se conseguir uma distribuição com eficiência e menor custo possível tem que ser bem difundido e organizado todos os modais de transportes como rodoviário, ferroviário, marítimo, dutoviario e aéreo.

O transporte de cargas no Brasil e composto maciçamente pelo rodoviário com $67,4 \%$ e o restante corresponde aos transportes ferroviário $(18,2 \%)$, hidroviário $(11,4 \%)$ e dutoviário (3\%).

O transporte marítimo no Brasil já foi muito utilizado nas décadas passadas devido a costa brasileira ser gigantesca, o Brasil e uma pais favorecido pela sua costa marítima, rios e grandes lagos navegáveis, trata-se de um país com uma costa navegável de $7.500 \mathrm{~km}$ de extensão, com mais de 30 portos organizados e inúmeros terminais de uso privativo, o país possui uma grande concentração costeira de indústrias de produção e consumo, com $80 \%$ da população vivendo entre as regiões litorâneas e a até $200 \mathrm{~km}$ da costa, isso tem um grande potencial para a cabotagem no brasil.

Porem a falta de infraestrutura de transportes no Brasil afeta diretamente o desenvolvimento da cabotagem no país. Mesmo sendo o modal menos poluente, seguro em relação a sinistros de roubos e acidentes a cabotagem sofre com a falta de infraestrutura nos portos brasileiros, a burocracia também e um entrave que cria barreiras e freia muito o desenvolvimento, e a falta de infraestrutura de integração entre os elos dos modais, o processo 
não e sustentável se torna uma processo cíclico que gera muitas dificuldades para se chegar ao objetivo mais promissor, outro entrave também já bem conhecido e a falta de vontade politica em se desenvolver e gerar subsídios para esse modal tão promissor.

A cabotagem tem como principais produtos transportados os graneis sólidos ou seja minérios, cereais, sal marinho, açúcar e fertilizantes, graneis líquidos como petróleo e derivados, álcool, combustíveis, produtos químicos diversos e gás liquefeito e carga geral solta ou conternizada que são alimentos, maquinas, eletrodomésticos, eletrônicos, veículos, bobinas de papel ou aço, botijões de gás.

\section{METODOLOGIA}

A metodologia deste artigo está basicamente relacionada com pesquisa bibliográfica, baseado nos principais autores e suas definições.

Quanto aos meios, empregou-se a pesquisa bibliográfica, se usada em materiais já publicados como livros, artigos científicos e sites especializados. Cervo e Bervian (1996) definem a pesquisa bibliográfica dizendo que:

A pesquisa bibliográfica procura explicar um problema através de referências teóricas publicadas em documentos. Pode ser realizada independentemente ou como parte da pesquisa descritiva ou experimental. Em ambos os casos, busca conhecer e analisar as contribuições culturais ou científicas do passado existentes sobre um determinado assunto, tema ou problema. (CERVO; BERVIAN, 1996, p. 48).

\section{RESULTADO \\ TRANSPORTE MARÍTIMO}

Logística está presente no transporte marítimo, ela pode ser responsável por agregar valores, tempo e lugar a seus produtos diante de seus consumidores, ou seja, aumenta a acessibilidade do produto, no tempo exigido pelo consumidor. (ROCHA, 2003).

o transporte é uma atividade necessária à sociedade e produz uma grande variedade de benefícios possibilitando a circulação das pessoas e das mercadorias utilizadas por elas e, por consequência, a realização das atividade sociais e econômicas desejadas. No entanto, este transporte implica em alguns efeitos negativos [...] (VASCONCELLOS, 2006, p.11).

A infraestrutura marítima brasileira é composta pela via navegável de acesso ao porto e é financiada exclusivamente por meio de recursos que vem diretamente do Orçamento Geral da União (OGU) e cobrança por parte da autoridade portuária de tarifas que são para manter a profundidade, largura, sinalização náutica e área de fundeio em condições de atender às embarcações na carga de descargas nos portos, A infraestrutura portuária também tem como fonte de receitas as tarifas cobradas pela autoridade portuária, além de recursos do OGU, com o intuito de garantir, principalmente, a segurança na atracação de embarcações e na movimentação de cargas. A infraestrutura e superestrutura dos terminais portuários arrendados, por seu turno, são financiadas por recursos privados provenientes de capital próprio e de terceiros, ou seja, investidores internos e externos, que foram a estrutura de capital dos arrendatários.

O Brasil tem com o grande diferencial o seu território que pode ser utilizado em grandes escalas por diversos modais, mas quando nos falamos de transportes marítimos o Brasil tem uma grande vantagem devidos os seus recursos naturais, tanto pela a sua grande capacidade de movimentação de cargas pela costa ou por rios. 
De acordo com Keedi e Mendonça (2000), a navegação de cabotagem significa o transporte de cargas entre portos marítimos nacionais, ou entre portos marítimos nacionais e portos interiores do país localizados em rios.

A cabotagem segundo Rodrigues (2007, p. 91): "E o termo que define o transporte marítimo ao longo da costa brasileira, de Rio Grande a Manaus". Dessa forma, a cabotagem conceitua-se como a navegação entre portos marítimos de um mesmo país.

Para Valente (2009), as definições existentes para a navegação de cabotagem são inúmeras, algumas tomam por base a legislação vigente, outras a rotina operacional, entretanto todas apoiam num eixo em comum que é o transporte de cargas entre portos de um mesmo país.

A navegação de cabotagem pode ser considerada uma das grandes saídas para os atuais gargalos da logística enfrentados nos dias atuais. Com enorme potencial operacional e ainda pouco desenvolvida no Brasil, a cabotagem se mostra como meio eficaz para a supressão do trânsito pesado de caminhões nas estradas nacionais, colocando-se como uma excelente opção para a mudança da matriz de transportes. (CASTROJÚNIOR, 2011, p. 261).

A navegação de cabotagem apresenta um potencial bem claro e evidente e vem sendo conceituada como possível solução para matriz de transporte nos próximos anos que vem sofrendo e muito com a falta de organização por parte de investimentos do setor governamental. Mesma diminui o fluxo de veículos pesados nas rodovias e influencia de forma positiva na conservação e medidas sustentáveis ao meio ambiente que sofre muito com a falta de eficiência.

\section{TRANSPORTE DE CARGAS}

O Transporte marítimo no Brasil de cargas via cabotagem e basicamente o transportes de mercadorias entre os portos brasileiros ou de uma ponto ao outro, essa modalidade e transporte no Brasil já e utilizada a muito tempo, mas com os investimentos no modal rodoviário o transporte marítimo via cabotagem acabou sendo deixado de lado momentaneamente, mas aos passar os anos a cabotagem esta tendo uma grande evidencia pela sua grande capacidade de movimentação de cargas que por via rodoviária se tornaria inviável devido a grande distancia do ponto $A$ ao ponto $B$, no Brasil tem empresa que já são especializadas nesse tipo de transportes de cabotagem uma dessas empresas que a Mercosul Line, ela oferece o serviço de toda a costa Brasileira e atingi também alguns países da América do Sul como a Argentina, abaixo podemos observar a sua rota de subida e a de descida pela costa Brasileira. 
Figura 1 - Linhas de navegação da empresa Mercosul Line.

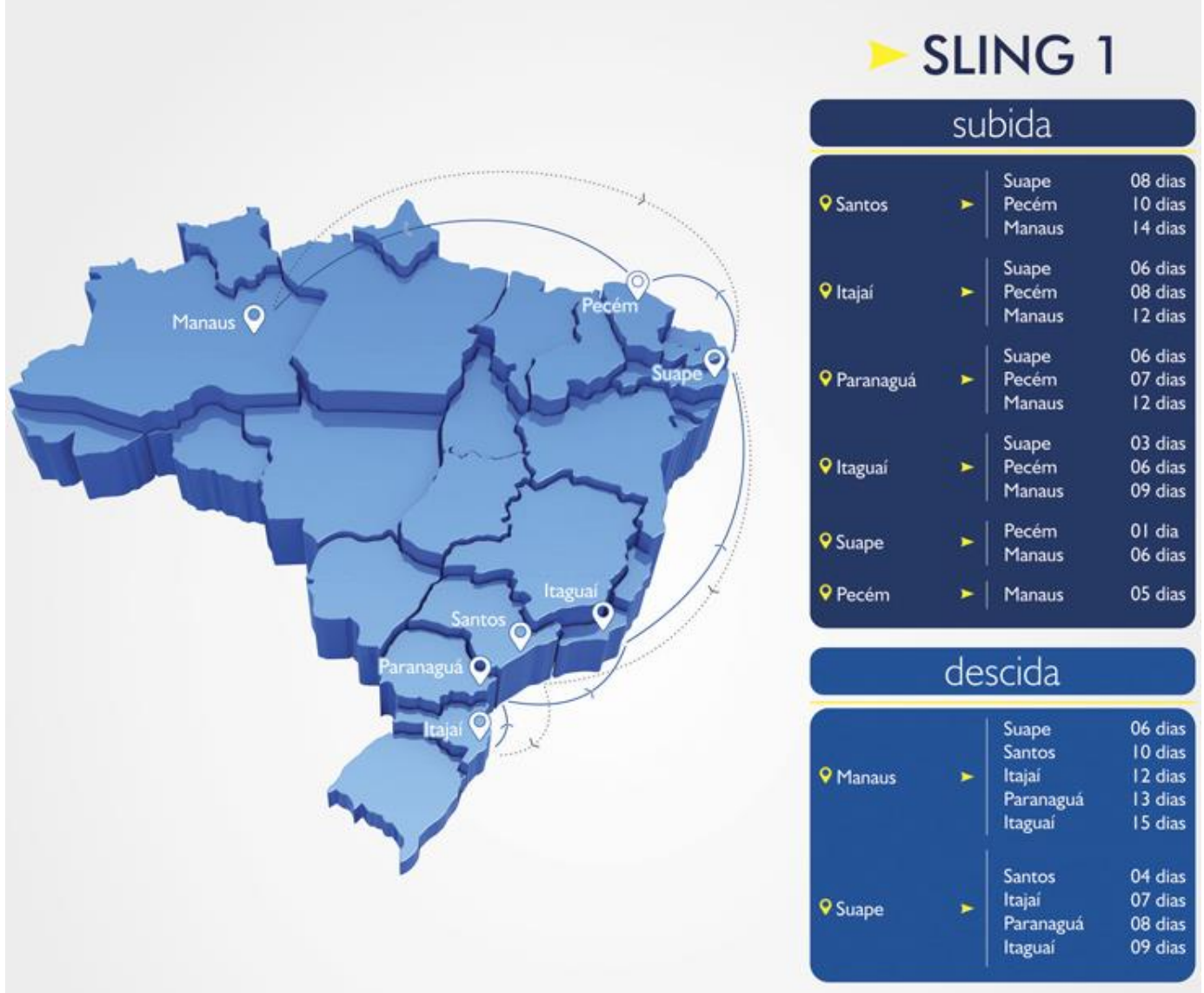

Fonte: Mercosul Line, 2017.

Figura 2 - Linhas de navegação da empresa Mercosul Line.

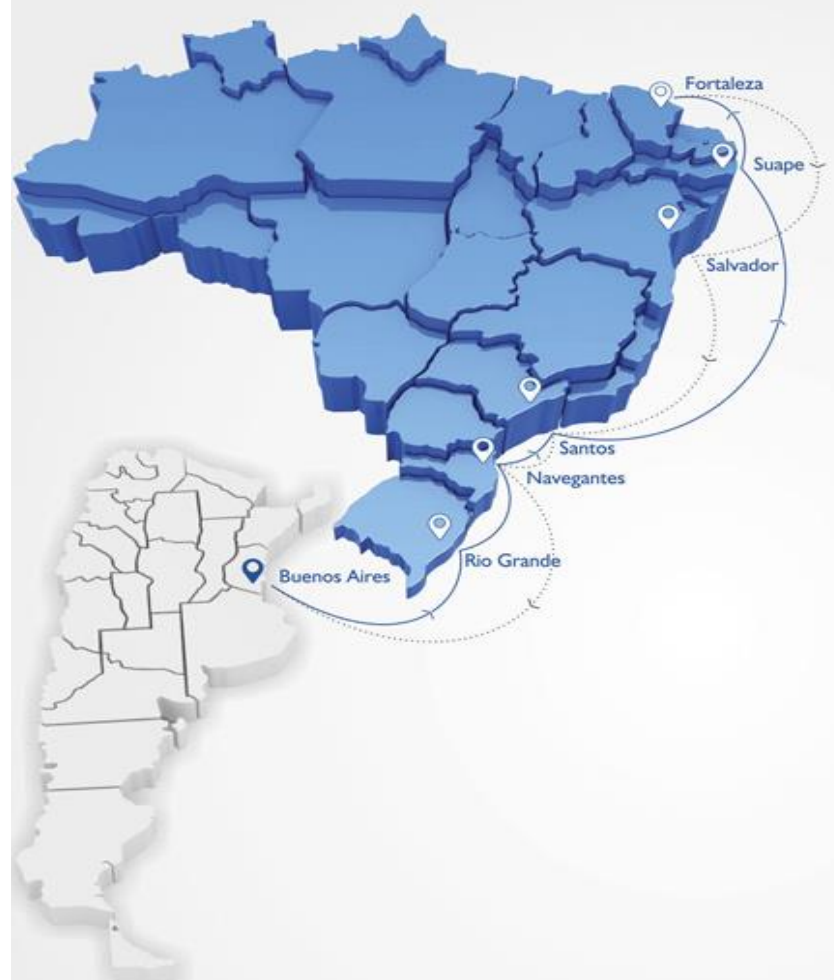

SLING 2

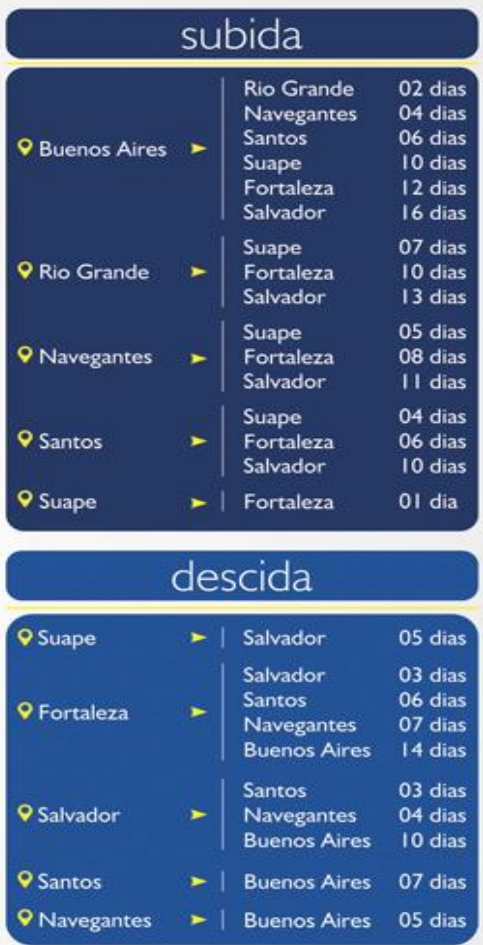

Fonte: Mercosul Line, 2017. 
A cabotagem tem enfrentado grandes desafios nos últimos anos que tem um crescimento satisfatório em relação aos outros modais que estão sofrendo e muitos para redução de custos operacionais e outros problemas como infraestrutura de baixa capacidade em movimentação e também a falta de investimento do poder publico.

A grande vantagem da cabotagem e o custo operacional bem reduzido, ou seja, o custo unitário e baixo outra vantagem que se encontra na cabotagem são os redução substancial de sinistros com acidentes e furtos que ocorrem nas rodovias, menor consumo de combustível, capacidade de movimentação de grandes quantidades de cargas por longas distâncias, custo logística inferior ao modal rodoviário, desafogamento das estradas e redução do nível de investimento e manutenção e construção de novas rodovias, já em relação as desvantagem podemos destacar a falta de integração com outros modais como rodoviário e ferroviário, a falta de estrutura como acima já citada revela que a os gargalos que dificultam o desenvolvimento do setor e impedem a eficaz integração com os modais e a falta de investimento por parte governamental também cria grande dificuldade a burocracia nos portos para atracamento gera grande demora na operação.

Para Castro Júnior (2011):

Além dos problemas estruturais e institucionais, há ineficiência dos portos nacionais e inexistência de centros de consolidação de carga para a cabotagem bem como péssima acessibilidade aos portos o que, somados à sua onerosidade excessiva, constituem grandes problemas para o desenvolvimento da cabotagem no país. (CASTRO JÚNIOR, 2011, p.482).

A capacidade insuficiente de terminais de contêineres e infraestrutura de acesso portuário resulta na demora da atracação dos navios e a utilização parcial da capacidade dos mesmos. A baixa prioridade de acesso aos portos dificulta a regularidade das escalas, resultando no excesso de burocracia no despacho das cargas.

\section{DISCUSSÃO}

O trabalho de pesquisa veio para evidenciar os desafios e as perspectivas para o futuro do transporte via cabotagem na Brasil os maiores desafios encontrados foram os entraves burocráticos e falta de investimento necessário para que se essa modalidade conseguia ser o transportes ideal para todo o território nacional, uma vez que a sua grande capacidade de transporte já foi vem evidenciada, a sua economia gerada a cada movimentação realizada, se ocorrer os investimentos necessário e excluindo os gargalos com os outros modais a economia vai ser gigantescas para todas as esferas envolvidas no transportes de cargas no território Brasileiro, a consolidação definitiva da cabotagem no Brasil demanda, além de providencias para eliminação ou minimização dos entraves já existentes, o desafio a ser enfrentado recai necessariamente no governo federal que tem essa missão que só ele pode resolver com medidas certeiras e providencias cirúrgicas para se ter maior competitividade com as outras economias, o Brasil sofre e muito com essa falta de gestão e fica basicamente no esforço incansável dos operadores que buscam as melhores situações para o transporte eficaz e sim gerando riquezas para o Brasil.

\section{REFERÊNCIAS BIBLIOGRÁFICAS}

CERVO, Amado Luiz; BERVIAN, Pedro Alcino. Metodologia científica. 4. ed. São Paulo: Makron Books, 1996.

ROCHA, Paulo Cesar Alves. Logística \& Aduana. 2 ed. São Paulo: Aduaneiras, 2003. 
VASCONCELLOS, Eduardo Alcântara de. Transporte e meio ambiente: conceitos e informações para analise de impactos. São Paulo: Annablume, 2006.

MERCOSUL. Página brasileira do MERCOSUL. Disponível em: http://www.mercosulline.com.br/servicos rota.php

CASTRO JÚNIOR, PASOLD, Cesar Luiz (Org.). Direito portuário, regulação e desenvolvimento. 2. ed. Belo Horizonte: Fórum, 2011.

KEEDI, MENDONÇA, Paulo C.c. de. Transportes e seguros no comércio exterior. 2. ed. São Paulo: Aduaneiras, 2000.

RODRIGUES, Paulo Roberto Ambrosio. Introdução aos sistemas de transporte no Brasil e à logística internacional. 4. ed. São Paulo: Aduaneiras, 2007.

VALENTE, José Augusto. Logística e transportes: Logística marítima para cabotagem terá aportes que ampliam movimentações. Disponível em:

<http://logisticaetransportes.blogspot.com/2009/02/logistica-maritima-paracabotagem tera.html>. Acesso em: 04 mar. 2017 